\section{Case Reports in Dermatology}

\title{
A Case of Vulvar Schwannoma Mimicking Epidermoid Cyst
}

\author{
Jingwen $\operatorname{Tan}^{\mathrm{a}}$ Jia Chen ${ }^{\mathrm{b}}$ Lianjuan Yang ${ }^{\mathrm{a}}$ \\ ${ }^{a}$ Department of Medical Mycology, Shanghai Dermatology Hospital, Shanghai, PR China; \\ ${ }^{b}$ Department of Pathematology, Shanghai Dermatology Hospital, Shanghai, PR China
}

\section{Keywords}

Vulvar schwannoma $\cdot$ Schwannoma $\cdot$ Epidermoid cyst

\begin{abstract}
Schwannoma is a generally benign tumor of the peripheral nerve sheath arising from Schwann cells. Most schwannomas are found on the head and neck. Here, we describe a rare case of benign vulvar schwannoma located at the labium majus which was similar to an epidermoid cyst in clinical appearance.

(C) 2018 The Author(s)

Published by S. Karger AG, Basel
\end{abstract}

\section{Introduction}

Schwannoma (also known as neurilemmoma) is a generally benign tumor of the peripheral nerve sheath with $<1 \%$ of tumors becoming malignant [1]. It is arising from Schwann cells and was firstly named by Masson in 1932. Approximately 25-45\% of schwannomas are found on the head and neck but rarely on the vulva [2,3]. According to the literature, the age of patients with vulvar schwannoma ranges from 5 to 84 years $[1,4]$, and the diameter rang-

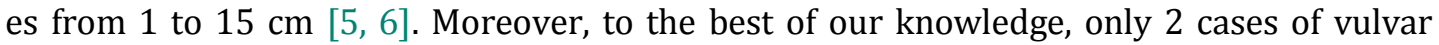
schwannomas which were located on the labium majus have been reported so far $[7,8]$. Here, we describe a case of benign vulvar schwannoma involving the labium majus which was mimicking an epidermoid cyst. 


\section{Case Report}

A 58-year-old Chinese woman was referred to our clinic in July 2015 for a painless palpable vulvar mass, which had been slowly growing for approximately 10 years. Although no ulceration or bleeding had been noticed, she felt mild discomfort occasionally. On physical examination, there was a circumscribed solid subcutaneous mass located on the left labium majus, approximately $1 \mathrm{~cm} \times 1 \mathrm{~cm}$ in diameter. It was oval, mobile (no conglutination with surrounding tissue), elastic in consistency, and not tender. The overlying skin was smooth with a blue-gray color, and a black dot was noticed in the middle (Fig. 1). Other parts of the external genitalia were completely normal, and there was no inguinal lymphadenopathy. The initial diagnosis was epidermoid cyst. Then, a surgical excision was performed.

Histopathological examination with HE staining showed a typical schwannoma (Fig. 2). The tumor was formed by packed spindle cells arranged in areas of high cellularity with little stromal matrix (Antoni A), and cystic degeneration was noticed. Nuclear palisading (Verocay bodies) and regions of loosely packed spindle cells as well as cells with small round nuclei (Antoni B) were seen in a hypocellular area. Immunohistochemistry showed that interweaving bundles of spindle cells were strongly positive for S-100 protein (Fig. 3) and negative for CD34 and NF, which confirmed the diagnosis of benign schwannoma.

\section{Discussion}

Schwannoma is always solitary, encapsulated, and slowly growing [9]. Clinical symptoms may vary depending on which nerve is affected, but it is mostly painless. Therefore, it is usually noticed by chance. When we come across a vulvar mass, it is hard to make a diagnosis according to clinical characteristics. Differential diagnoses, such as neurofibroma, which is another benign tumor of the peripheral nerves, should be considered [4]. Epidermoid cyst, labial cyst, mesenchymal tumors, including lipoma, liposarcoma, fibrosarcoma, and angiosarcoma, and Bartholin cyst are all essential differential diagnoses [4, 10]. Imaging studies, such as ultrasonography, can be applied in nonaggressive diagnostics to specify the cystic or solid characteristics of the mass. But only histopathology with characteristic appearance can help to confirm the diagnosis. The histological hallmark of schwannoma is a combination cellular pattern of Antoni type A (a tightly packed sheath of spindle cells arranged in palisade and swirling patterns) and B areas (loosely packed spindle cells and cells with small round nuclei) [1,9]. In addition, nuclear palisading and Verocay body-like structures without mitosis are typical schwannoma features. Immunohistochemistry of S-100 protein is highly recommended after the histopathological assay. A strongly positive stain for S-100 protein appears in benign schwannomas, while malignant schwannomas have lost the capacity to synthesize S-100 protein [1].

The first choice of treatment is surgical removal. For benign schwannomas, complete excision is enough. Prognosis is generally excellent following the operation. However, an incomplete resection, which could lead to a relapse, has been reported [11]. A long-term follow-up visit is necessary after surgical removal.

Compared to previously reported cases of vulvar schwannoma, our patient is distinctive due to the difficulty in distinguishing the schwannoma from epidermoid cyst. The lesion was a well-demarcated subcutaneous nodule and had a clinically visible central punctum, which is in accordance with epidermoid cyst. Thus, the initial diagnosis of epidermoid cyst was made. But the diagnosis of schwannoma was confirmed by histopathological examination. 
The black dot might be pigmentation or an opening structure like a blackhead. Although schwannoma involving the labium majus is a rare finding, we suggest that it should be considered as a differential diagnosis of any vulvar mass.

\section{Acknowledgment}

We thank the patient for granting permission for publishing this information. We appreciated the work of the surgical and pathological teams involved in the case. This study was supported by the National Natural Science Foundation of China (81573063), Natural Science Foundation of Shanghai (16ZR1431300), and Shanghai Municipal Commission of Health and Family Planning (20154Y0196). The funders had no role in study design, data analysis, decision to publish, or preparation of the manuscript. This study does not present any conflicts of interest for the authors.

\section{Statement of Ethics}

The patient's informed consent was obtained.

\section{Disclosure Statement}

The authors have no conflict of interest to disclose.

\section{References}

1 Park ST, Kim HM, Shin MK, Kim JW: An unusual case of vulvar schwannoma. World J Surg Oncol 2015;13:139.

2 Malone JP, Lee WJ, Levin RJ: Clinical characteristics and treatment outcome for nonvestibular schwannomas of the head and neck. Am J Otolaryngol 2005;26:108-112.

-3 Pantè S, Terranova ML, Leonello G, Fedele F, Ascenti G, Famulari C: Perineal schwannoma. Can J Surg 2009;52:E8-E9.

4 Yegane RA, Alaee MS, Khanicheh E: Congenital plexiform schwannoma of the clitoris. Saudi Med J 2008;29:600-602.

5 Bozkurt M, Kara D: Giant vulvar schwannoma: a case report. Acta Med Iran 2013;51:427-429.

6 Jia G: A case of giant schwannoma of vulva. J Pract Obstet Gynecol 2008;9:562.

7 Bryan WE: Neurilemmoma of the vulva. J Obstet Gynaecol Br Emp 1955;62:949-950.

8 Zhang S: Ultrasound diagnosis of vulvar schwannoma: a case report. Med Innov China 2011;8:164.

-9 Yamashita Y, Yamada T, Ueki K, Ueki M, Sugimoto O: A case of vulvar schwannoma. J Obstet Gynaecol Res 1996;22:31-34.

10 Fong KL, Bouwer H, Baranyai J, Jones RW: Ancient schwannoma of the vulva. Obstet Gynecol 2009;113:510-512.

11 Maneschg C, Rogatsch H, Bartsch G, Stenzl A: Treatment of giant ancient pelvic schwannoma. Tech Urol 2001;7:296-298. 


\section{Case Reports in Dermatology}

\begin{tabular}{l|l}
\hline Case Rep Dermatol 2018;10:41-45 \\
\hline DOI: 10.1159/000487125 & $\begin{array}{l}\text { C 2018 The Author(s). Published by S. Karger AG, Basel } \\
\text { www.karger.com/cde }\end{array}$ \\
\hline
\end{tabular}

Tan et al:: A Case of Vulvar Schwannoma Mimicking Epidermoid Cyst

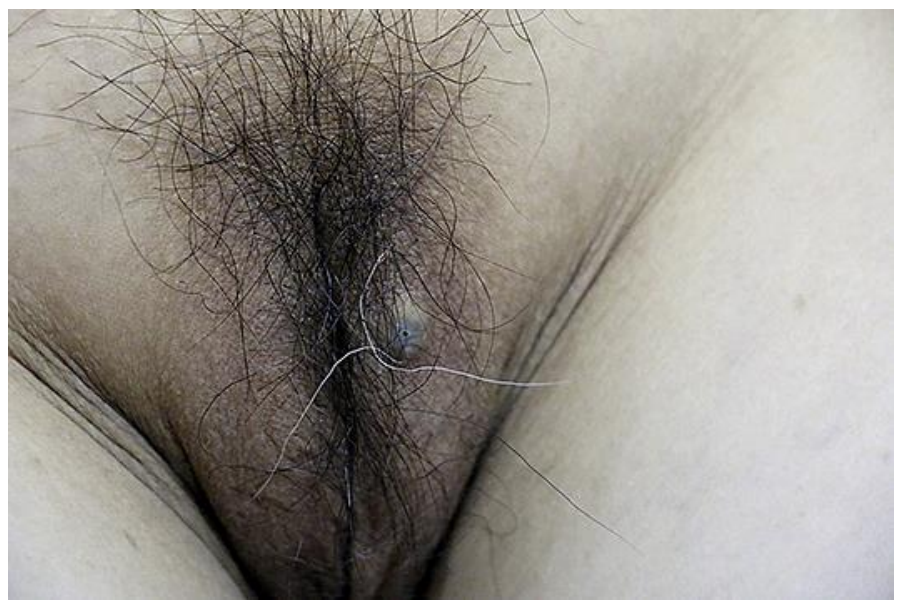

Fig. 1. General view of the vulvar schwannoma before surgical resection: a round subcutaneous nontender solitary tumor with a blue-gray color and a black dot on the left labium majus.
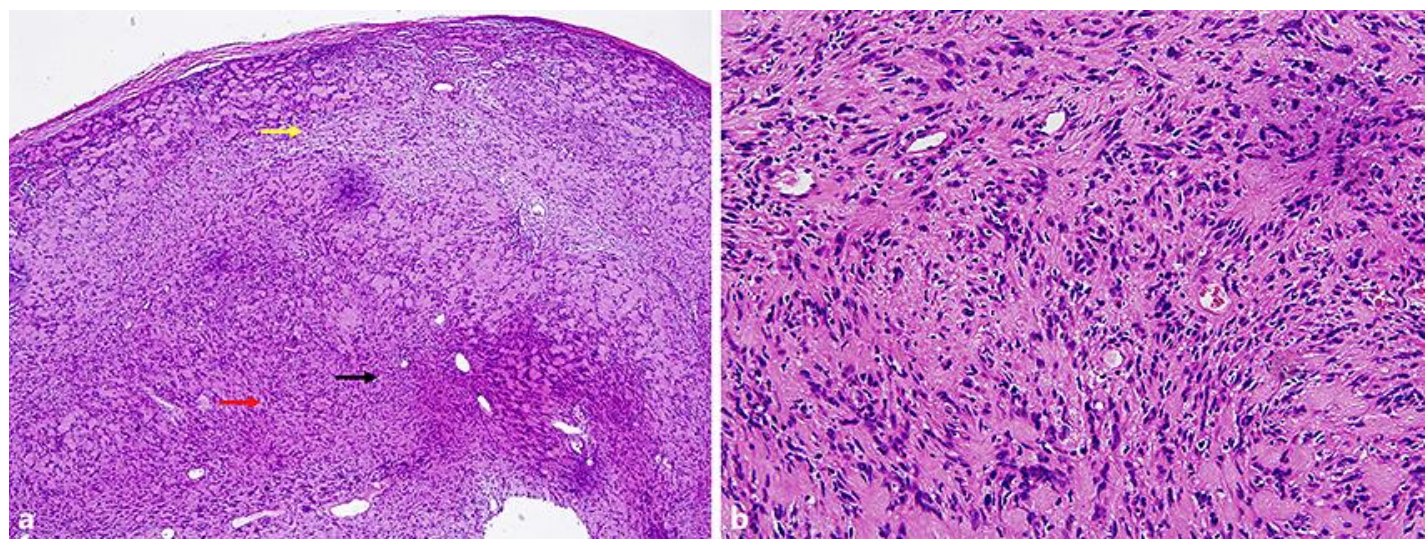

Fig. 2. Histopathological examination showed a palisade pattern and a swirling pattern, forming Verocay bodies. a HE stain, $\times 40$. b HE stain, $\times 200$. Red arrow, Antoni A area; yellow arrow, Antoni B area; black arrow, Verocay bodies. 


\section{Case Reports in Dermatology}

Case Rep Dermatol 2018;10:41-45 DOI: $10.1159 / 000487125$

(C) 2018 The Author(s). Published by S. Karger AG, Basel www.karger.com/cde

Tan et al.: A Case of Vulvar Schwannoma Mimicking Epidermoid Cyst

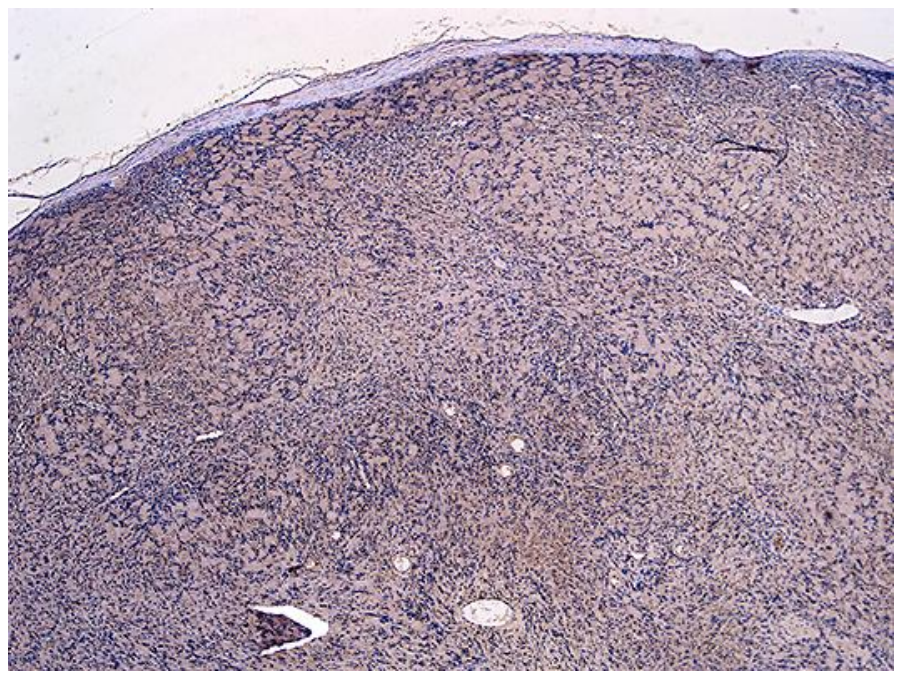

Fig. 3. Immunohistochemical examination showed that the spindle cells were diffusely positive for S-100 protein. 